\title{
Matrimonios y algo más. Blanca Podestá y Alberto Ballerini en clave artística, afectiva y laboral
}

\author{
Lía Noguera \\ CONICET - Universidad Nacional de las Artes - Universidad de Buenos Aires, Argentina \\ liasabrinanoguera@gmail.com
}

Fecha de recepción: 30/08/2021. Fecha de aceptación: 05/10/2021

\begin{abstract}
Resumen $^{1}$
A partir de los estudios realizados en el marco de una beca Investiga Cultura otorgada por el Ministerio de Cultura de la Nación Argentina para realizar en el Fondo Documental Jacobo De Diego, perteneciente al Instituto Nacional de Estudios de Teatro (Buenos Aires Argentina), nos proponemos dar cuenta en este artículo de las relaciones artísticas, económicas y afectivas de aquello que hemos denominado compañías-familias. Para ello, nos concentraremos en un matrimonio paradigmático del árbol genealógico de la familia Podestá en Argentina: Blanca Podestá y Alberto Ballerini.
\end{abstract}

Palabras clave: trabajo artístico- teatro argentino- siglo XX- compañías- afectos- PodestáBallerini.

\section{Marriages and Something Else. Company-Families in the Argentine Theater Scene: Blanca Podestá and Alberto Ballerini}

\footnotetext{
Abstract

Based on our studies at the the Jacobo De Diego Archive of the National Institute of Theater Studies (Buenos Aires, Argentina), carried out within the framework of an Investiga Cultura grant of the national Ministry of Culture, we aim analyze in this article the artistic, economic and affective relationships of what we have called

1 Esta investigación se inscribió en el marco de una beca Investiga Cultura otorgada por el Ministerio de Cultura de la Nación Argentina en el período (2019-2020) para realizar en el Archivo INET (Argentina). Agradecemos la colaboración de todo el personal de este Instituto y, en especial, a su directora, Dra. Laura Mogliani, por la labor incansable que realizan por la preservación y difusión de nuestro pasado y presente teatral. En estudios previos (Noguera, 2017) dimos cuenta de las características estéticas y laborales de las compañías de José Podestá. La investigación global en el marco de la mencionada beca comprendió el estudio de tres miembros de la familia Podestá: Jerónimo, Pablo y Blanca. Aquello que presentamos aquí es una versión especial que profundiza solo en el estudio del matrimonio Blanca Podestá y Alberto Ballerini.
} 
company-families. In order to do so, we will focus on a paradigmatic marriage of the Podestá family tree in Argentina: Blanca Podestá and Alberto Ballerini.

Keywords: artistic work- Argentine theater- 2oth century- companies- affections- PodestáBallerini.

El estudio del árbol genealógico de la familia Podestá, una familia fundante en lo que refiere al pasado teatral argentino y que evidencia más de cien miembros (en su gran mayoría artistas), fue trazado por Jacobo De Diego en sus cuadernos y estos se encuentran en el Fondo documental que lleva su nombre, en el Instituto Nacional de Estudios de Teatro (INET-Argentina). En efecto,

Jacobo de Diego (1908-1993) donó su archivo personal al Instituto Nacional de Estudios de Teatro (INET), y con este material se conformó el denominado "Fondo Jacobo de Diego", que forma parte del Archivo Documental Histórico del INET. Los primeros documentos fueron donados personalmente por Jacobo A. de Diego en el transcurso de sus dos últimos años de vida (1992-1993), ya organizados por él en unidades temáticas y constituyen la mayor parte del fondo (61 cajas). Luego del fallecimiento de Jacobo de Diego, su familia donó el resto de la documentación que integra el fondo (...). Este archivo fue conformado desde 1928 hasta 1993, y se refiere fundamentalmente a la historia del teatro argentino y latinoamericano desde sus orígenes y hasta finales del siglo XX. También incluye materiales sobre tango y cultura popular porteña, temas a los que Jacobo de Diego se dedicó especialmente, así como sobre cine, ya que fue crítico tanto teatral como cinematográfico entre 1928 y 1963, en medios como los diarios Noticias Gráficas y última Hora, y en la revista Mundo Radial. (Mogliani, https://inet.cultura.gob.ar/media/ uploads/site28/multimedia/el_legado_de_jacobo_de_diego_al_instituto_nacional_de_estudios_de_teatro.pdf)

Este material, junto a las diferentes anotaciones a él vinculadas, las fotografías, los contratos laborales, cartas, manuscritos, programas de manos, críticas y los estudios relacionados con la sociología de familia, los afectos y el trabajo artístico, nos permiten dar cuenta de ciertas características de las compañías teatrales de fines del siglo XIX y mediados del XX en Argentina y que fueron llevadas adelante por sus integrantes. Compañías que, dado el lazo de consanguineidad y los contratos matrimoniales establecidos (en la gran mayoría con otros artistas del campo cultural de la época), hemos denominado como compañías-familias. En ellas, los roles eran fijos y sus avances dentro de los estratos artísticos dependían del desarrollo que se obtenía dentro del mismo grupo y del reconocimiento del público. Estos roles, afirma Pellettieri, "eran fundamentales a la hora de distribuir las ganancias y para acceder a los papeles de mayor jerarquía había que hacer carrera dentro de la compañía" (2002:147). Así también, las compañías, y en especial las de circo, tenían una estructura en la cual tanto hombres, mujeres y niños trabajaban a la par y el oficio se aprendía mediante la transmisión de saberes de los adultos y la imitación por parte de los restantes integrantes. Tal es el caso de las compañías que llevaron adelante los diferentes integrantes de la familia Podestá en la Argentina y cuyo padre fundador, como también de nuestro teatro nacional, se reconoce a José "Pepe" Podestá.

Vargas Islas, en su artículo titulado "El amor: ¿rehén de la familia?", realiza un estudio sobre las relaciones entre amor y familia, a la vez que evidencia los cambios que se establecen entra la familia patriarcal y la familia moderna, producto esta del surgimiento de los Estados Modernos. Si en la familia patriarcal el núcleo y la organización interna se centraban en el hombre y los vínculos sociales eran determinantes para la constitución de los vínculos y su funcionamiento, en la familia moderna la incidencia de lo social se repliega y es la importancia del mundo privado aquello que se privilegia. 
En este sentido, del rasgo público caracterizador de la familia patriarcal se pasa a los sentimientos y organización a puertas adentro que repercute y determina nuevas formas de existencia a la vez que lo laboral deja de ser un vínculo fundamental de los lazos familiares. Así lo explica Vargas Islas en relación con la familia patriarcal:

Matrimonio y familia eran un asunto social, una cuestión de la comunidad, una responsabilidad compartida. Las funciones de las que el grupo, la familia y aun el sujeto mismo se hacían cargo tenían un sentido social amplio, un significado colectivo que dotaba a los sujetos de un sentimiento de integración y pertenencia. (1996: 128)

A partir de estas reflexiones y las fuentes documentales halladas en el INET, consideramos que la constitución de las compañías-familias teatrales de los Podestá que comprende esta investigación responde a un paradigma de organización que halla su significación en el encabalgamiento de las dos formas familiares analizadas por Vargas Islas. Es en ese entre lo patriarcal y lo moderno en el que estas compañías sustentan tanto sus formas de relacionarse artísticamente, afectivamente y laboralmente. Además, comprendemos que los vínculos laborales y afectivos de las compañíasfamilias determinan un lazo de dependencia que no siempre es definitivo, pero que permite, en los casos que se rompan, replicar iguales asociaciones, distribuciones y organizaciones para las nuevas compañías-familias. Así lo observamos en las rupturas que las compañías de José y Jerónimo (hermano mayor del primero) han tenido a comienzos del siglo XX, como así también, lo han experimentado las asociaciones y quiebres entre José y Pablo Podestá (hermano menor de ambos) y, posteriormente, las vinculaciones entre Blanca Podestá (hija de Jerónimo, sobrina de José y Pablo) y Alberto Ballerini (esposo de Blanca) a partir de su matrimonio.

Por tal motivo, teniendo en cuenta el extenso material biográfico sobre los artistas de nuestro corpus y que se hallan en el archivo INET, en general, y en el Fondo Jacobo De Diego, en particular (que revelan información poco analizada hasta el momento desde los estudios teatrales), creemos que el estudio de lo afectivo se constituye en una nueva forma de acceder a los documentos del pasado teatral argentino y permiten comprender las lógicas de funcionamiento económico, laboral y artístico de las compañías teatrales de la primera mitad del Siglo XX. Tal es el caso de la Compañía Ballerini-Podestá.

\section{Un amor entre tablas}

Blanca Podestá nació en La Plata en 1886 "cuando las compañías recorrían las campiñas del Río de la Plata, pernoctando bajo las carretas, allí donde la sorprendía la noche" (Máscara, 1944:18). Comenzó su carrera artística a los doce años en la obra Caín de García Velloso, en que realizó el reemplazo de María Podestá, "la rubia cantora", quien en ese momento estaba enferma. Ante esta ausencia, el autor le pidió a su director, Ezequiel Soria, que "reúna la compañía y que se pongan las mujeres en fila que de allí voy a sacar yo una actriz", recuerda Blanca en un reportaje (El hogar, 4 de octubre de 1957). Y así se hizo: la hija menor de Jerónimo Podestá fue elegida y con las indicaciones directoriales de Soria, las enseñanzas de su padre y los consejos de Velloso comenzó a perfilarse el futuro de esta gran actriz dramática. Luego de su debut, componiendo sus personajes a partir de la observación, la imitación de sus pares y ensayando delante del espejo (aspectos propios de la actuación popular en la cual nace), Blanca continuó con la representación de las obras dirigidas por Ezequiel Soria: El faro y La gaviota. Con respecto a este gran director artístico de nuestro pasado teatral, y en relación con su trabajo en la compañía de Jerónimo Podestá, Laura Mogliani señala que: 
Junto a esta compañía realizó una tarea semejante a la anterior (la de Pepe Podestá), facilitando la presentación de obras dramáticas de autores nacionales consagrados y asesorando sobre la labor de los actores y la puesta en escena. Su búsqueda de perfeccionamiento actoral coincidía con una preocupación estética por la puesta en escena, en ambos casos tendientes a avanzar hacia una mayor naturalidad. (2021: 302)

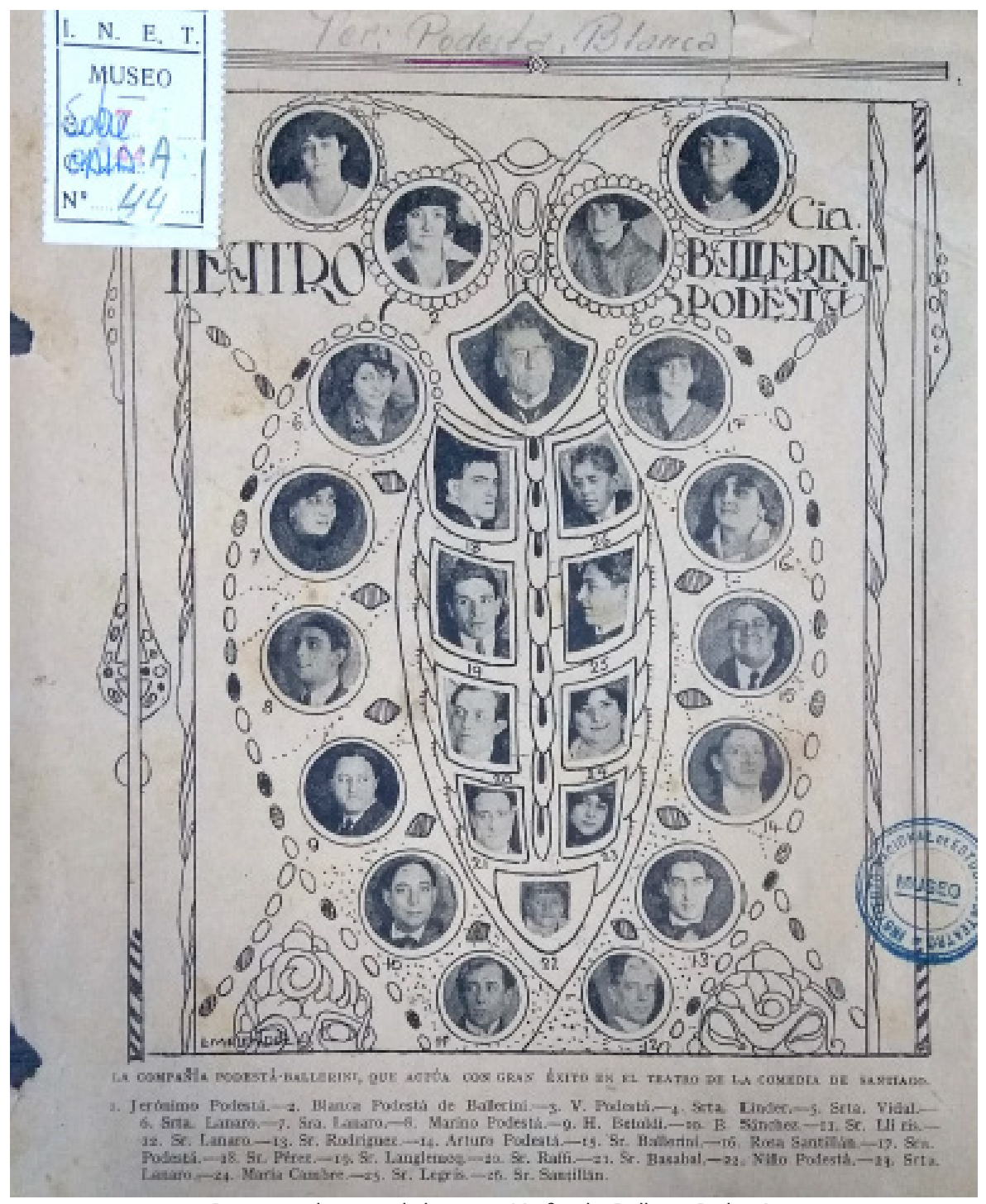

Programa de mano de la compañía-familia Ballerini-Podestá2

En 1906, Blanca estrenó, en el Teatro Nacional -cuyo dueño era su padre- las obras: Nuestros hijos y Moneda falsa de Florencio Sánchez y La cadena de Enrique García Velloso, entre otras. Durante el período 1912 y 1915, comenzó a trabajar con su tío Pablo y, junto a él, deslumbró en Las montañas de las brujas y El zonda de Julio Sánchez Gardel. Además, llegaron los éxitos de Florencio Sánchez: Barranca abajo, Los muertos y Enfamilia. 


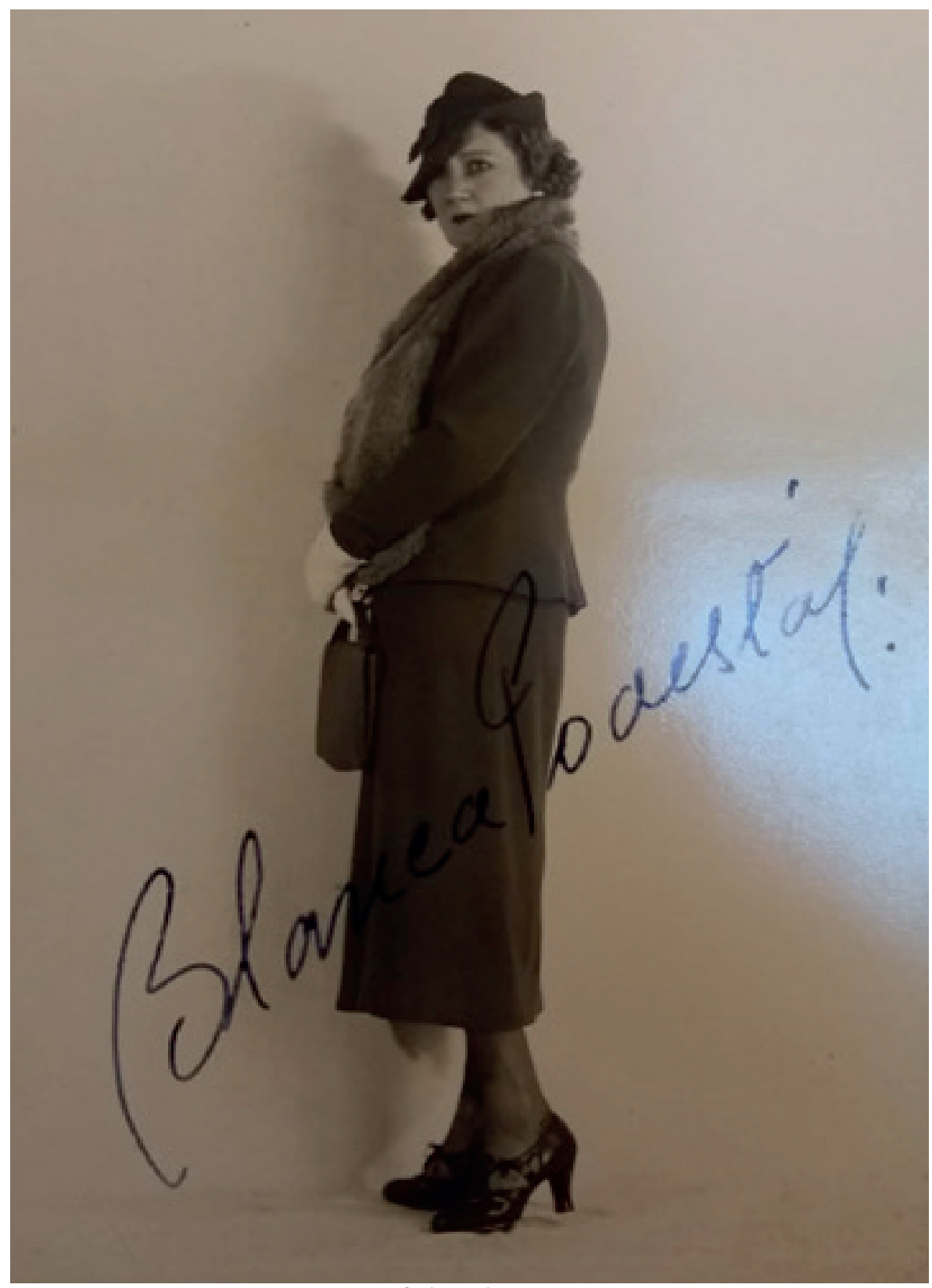

Foto autografiada por la actriz argentina.

Como actriz se inscribió en la poética de la actuación culta, que toma elementos de la dicción interpretativa y ensaya los primeros pasos de una actuación naturalista, despegándose de esta manera de sus raíces de actuación popular (que se iniciaron con su tío Pepe y su padre Jerónimo) y privilegiando la representación de personajes dramáticos que se destacaban por la intensidad y la veracidad. Así lo recuerda su sobrina, María Esther Podestá, en sus memorias (1985:72): "elegante e imponente, se debatió siempre entre su femineidad y su voz más bien ronca. Estaba más predispuesta para el drama que la comedia, y generalmente los dramas fueron los mejores aciertos de su carrera." Además, la crítica del momento destacó que un gran factor para la evolución y consolidación de su carrera fueron sus viajes a París en 1922 y 1926, puesto que tuvo oportunidad de ver actuar a Eleonora Duse en La Giocanda, actriz paradigmática de la poética actoral culta. Otro aspecto importante fue la visita de actores internacionales que le posibilitaron compartir escenarios porteños. Tal es el caso del actor y director francés Lugne Poe con quien representó El pescador de sombras de Sarment, con gran 
éxito de público y prensa. Asimismo, su teatro Smart recibió a Margarita Xirgu y Pedro López Lagar en las temporadas de 1937 y 1938, consolidando así su formación e intercambios procedimentales con actores representativos de la actuación culta. Cabe señalar que, parablemente a su exitosa carrera teatral y radiofónica, Blanca Podestá también participó de cuatro producciones cinematográficas: Tierra baja (1912), Camila O’Gorman (1913), Manuelita Rosas (1924) y Sendas cruzadas (1942).

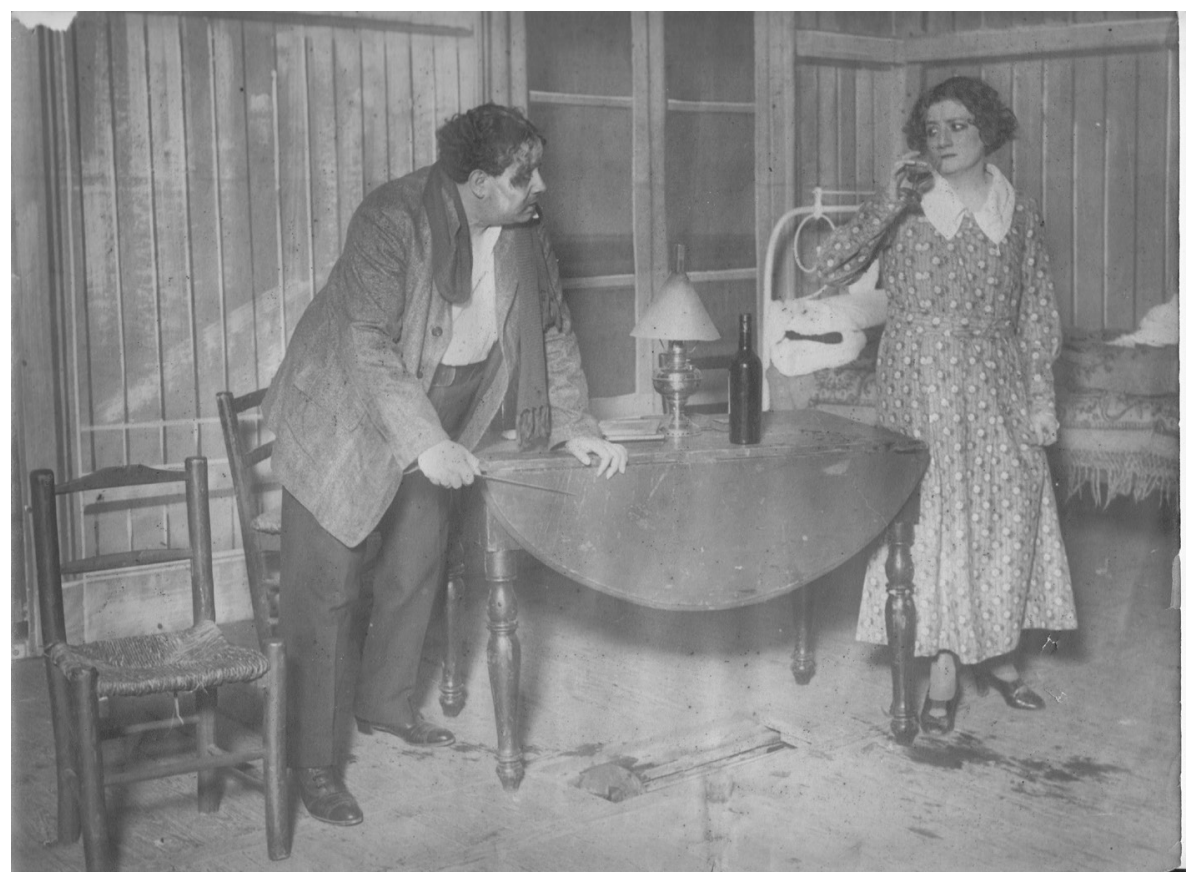

Blanca Podestá y Alberto Ballerini en Los venenos de G. Bosch

Su trayectoria artística es extensa, prolífera y alberga tanto la más destacada producción dramática nacional como internacional por tal motivo, en 1941, recibió un premio municipal por su actuación y el crítico más emblemático teatral de aquellos años, Jean Paul (que también ofició de jurado del galardón), confirma el lugar de centralidad de Blanca en los escenarios de Buenos Aires.

Juan Pablo Echague apareció como Jean Paul, en el panorama teatral porteño con los últimos resplandores de Enrique Frexas. Gran crítico como él, amasó su autoridad en el esfuerzo sin tregua, amparo de una disciplina de hierro. Su voluntad empeñosa, segura y vigilante como los picachos de su tierra sanjuanina sirvió a su talento joven nutriéndolo para la vasta labor. Y así fue cómo los espectadores esperaban sus juicios, seguros de conocer, a través de ellos, la verdadera calidad de la obra y de la interpretación. (El hogar, 4 de octubre de 1957)

Dice la carta fechada el 15 e mayo de 1940 en respuesta a los agradecimientos de la actriz al crítico teatral:

Era este un acto de estricta justicia que me fue grato apoyar, como demostración de reconocimiento y aplauso a la brillante actriz que de tan decisiva manera ha construido al desarrollo y auge del teatro nacional en toda una vida de devoción y en ocasiones de sacrificios.

Es importante señalar que, para la actriz, la función social y didáctica del teatro era fundamental, tal como lo afirma en un borrador manuscrito (Archivo Manuscritos, INET) de una entrevista brindada previamente al estreno de la obra La emboscada en la década del 30 : 
Prefiero aquellas obras que tengan una aspiración de bondad. Un fondo humano. Creo que el teatro es un admirable instrumento de educación y por ello debe cultivar tanto el sentimiento como la inteligencia. Considero al arte como un medio de perfeccionamiento del individuo y la colectividad. El arte como mera sensación estética aislada, el arte sin bondad, no me convence y no lo comprendo.

A fin de profundizar en los afectos a partir de documentos biográfico hallados en el Archivo INET y como un modo de demostrar el grado de incidencia que posee este factor en la formación, consolidación y, a veces, rupturas de las compañías-familias, nos interesa detenernos en los apuntes biográficos manuscritos sobre las vidas de José Podestá, Alberto Ballerini y Blanca Podestá, titulado "Comentarios dialogados algunos hechos de teatro, actores, etc." de autor anónimo. Este documento muestra aspectos que, si por un lado algunos de ellos fueron publicados en Medio siglo de Farándula, de José Podestá, por otro, revelan trayectorias y anécdotas poco difundidas hasta el momento en el campo teatral argentino. Así, en primer lugar, este material nos informa sobre el debut de Alberto Ballerini (nacido en Buenos Aires el 9 de noviembre de 1886), quien desde muy temprana edad soñó con ser actor. En estas memorias, el actor narra en primera persona su debut, aún siendo estudiante en una sociedad filodramática. Cuenta que, como la actriz principal no llegaba a la función, decidió vestirse de mujer y realizar el reemplazo a pesar de la incomodidad y casi imposibilidad de caminar con los zapatos de su compañera de elenco varios números más chicos. Recuerda el actor que ("Comentarios dialogados..." S/F: 3):

En el final del primer acto, el primer actor me increpaba duramente mi infidelidad en un parlamento que terminaba con una violenta escena en que me hacía caer a sus pies rendida y temblorosa. Y allí fue Troya. Rodé por el suelo en la pollera y la peluca desprendida por el brusco movimiento, voló en dirección a la primera fila de plateas; quedando yo en la más pintoresca de las actitudes. El encargado del telón abatatado no atinaba a echar la tela salvadora y una silbatina horrorosa tronó nuestros oídos. Levantame como pude, llegué al camarín donde recogí mi ropa y hui despavorido por la puerta del fondo, llevando la impresión de que mil sombras me seguían. Tomé un coche y di al auriga la dirección de mi casa, apareciendo con mis atavíos femeninos que con el miedo y la confusión me había olvidado de quitar. El asombro de mi familia llegó al paroxismo y excuso decirles, que todavía conservo cicatrices de la soberana paliza que me propinó mi viejo... con el palo de la escoba.

Luego de esta primera experiencia entre traumática y cómica, que expresa un sentir de época en relación con el trabajo artístico para aquellos que no pertenecían de manera directa a una compañía- familia y las cuestiones de género, su camino como actor siguió incansablemente y fue una figura notable de la escena nacional desde comienzos del siglo XX, principalmente, en comedias. Ballerini en 1903 tiene su primer acercamiento a la familia Podestá al ingresar en la compañía de Jerónimo. En 1907, formó parte de la compañía de Pablo Podestá y en 1911, retorna con Jerónimo con quien se lució en obras cómicas breves. Fue también actor en obras clásicas del repertorio argentino como: Gabino, el mayoral y Eclipse de sol, de Enrique García Velloso; Santos Vega, de Juan C. Nosiglia; El patio de Don Simón, de Mauricio Pacheco, entre muchas otras. En cuanto a su poética de actuación, ésta se sustentó en la popular y se caracterizó por el agregado de textos propios (procedimiento denominado morcilleo) y la individualización de sus personajes (Cilento, 2009), a través de diferentes recursos: vocales, movimientos corporales antinaturalistas, etc.

En un artículo escrito por Edmundo Guibourg, a raíz de los treinta años de trayectoria actoral que cumplió Balerrini, el crítico señala que el actor puso todo su empeño en conquistar su popularidad como artista del espectáculo y destaca el exotismo que lo 
acompañó: "camisas chillonas, trajes ribeteados, detalles diversos subrayados, han hecho que a gente de la calle no pasé por alto el pergoño de quien gozó de bastante boga como cómico y llevó a cabo famosas campañas como empresario". Esa trayectoria de más de treinta años como actor, de los cuales la mitad la ejerció compartiendo escenarios con actores de la talla de Florencio Parraviccini, Segundo Pomar, Luis Vittone, Blanca Podestá y Enrique Muiño. Junto a Roberto Casaux representó el Distinguido ciudadano y El caballo de bastos de Saldias; obras que lo consolidaron como gran actor del campo teatral.
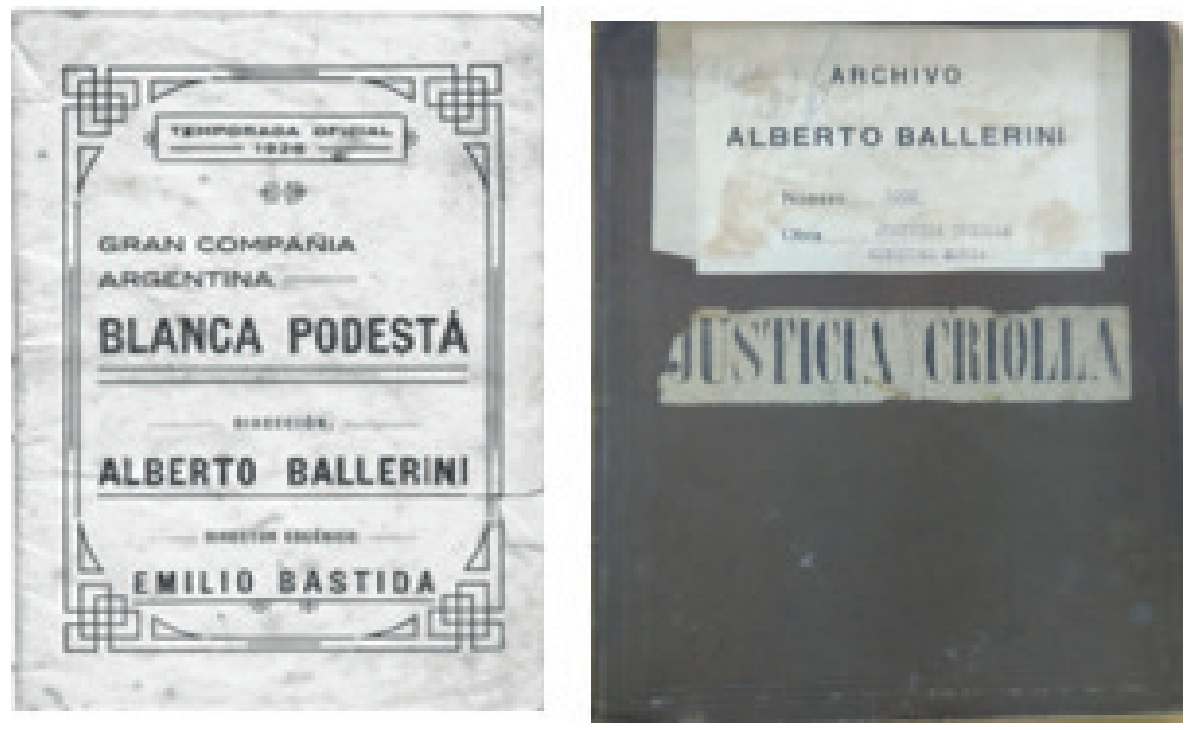

Se dedicó, también, a la escritura dramática -tanto como autor de obras, traducciones y adaptaciones- y su primera pieza fue El corset de mi mujer. Además, fue director de compañía, empresario y dueño de un teatro junto a Blanca Podestá. Si bien la crítica destacó su labor como actor, aún más han reconocido el papel que desempeñó en el campo como gestor cultural.

En segundo lugar, los apuntes biográficos hallados en el INET nos informan sobre la unión matrimonial y luego artística de Blanca y Alberto en 1910. Estos materiales nos muestran cómo el casamiento de los dos artistas principales de la compañía del padre de Blanca se produjo en la clandestinidad, puesto que, la hermana de Blanca también estaba enamorada de Alberto Ballerini. Afirma el biógrafo ("Comentarios dialogados..." S/F: 4):

El idilio entre Blanca Podestá y Ballerini se inició en el Teatro Nacional el 8 de enero, según los apuntes que guarda el actor Herrera. Entre ambos jóvenes parece que se estableció una corriente de simpatía que bien pronto se convirtió en amor. Estos amores eran conocidos por Pomar, Rossich, Vittone y Herrera, quienes habían jurado guardar el secreto a fin de no malograr la combinación puesto que, si se enteraba la familia de Blanca, los novios habrían tenido que luchar con casi insuperables dificultades. Ni la madre de Blanca ni su hermana Anita sospechaban de este amor.

No obstante, Blanca y Alberto se escaparon durante uno de los ensayos de la obra $\mathrm{La}$ pasión de la compañía de Jerónimo Podestá y, en el centro de la ciudad porteña, dieron el sí y marcharon, posteriormente, a la ciudad de Chivilcoy. Cuenta el biógrafo que, al enterarse de la noticia, la compañía estalló en asombro, pero aún más lo hizo Ana (la hermana de Blanca) quien terminó desahuciada y rompió -en parte- el camarín 
de Blanca. Este enlace afectivo, con sus pasiones y despechos, no sólo consolida lo afectivo en la pareja sentimental, sino también propicia una unión artística que se tradujo, posteriormente, en la formación de una compañía: Ballerini-Podestá, la posesión y dirección de un teatro, el Smart, desde 1924 y por un lapso de más de treinta años. Este teatro se ubicaba en la Avenida Corrientes entre Talcahuano y Libertad de la Ciudad de Buenos Aires, en la zona más emblemática de la actividad cultural porteña. Se inició el 30 de abril de 1914 como cine (Smart Palace) y el 27 de abril de 1922, dos años antes de la adquisición por parte de Blanca y Alberto, inauguró su actividad teatral con la obra El Burlador de mujeres de Belisario Roldán y actuaron: Angelina Pagano y Francisco Ducase.

Es importante destacar que los vínculos afectivos al interior de la pareja se traslucieron al campo teatral y operaron como bastión de la asociación laboral de esta nueva compañía-familia. La crítica del momento destacó al matrimonio de artistas como grandes renovadores de la escena porteña, así como también, celebraron las grandes figuras nacionales e internacionales que supieron conseguir. Entre los actores que intervinieron en las campañas conformadas por Blanca y dirigidas por Alberto, tal como lo documenta el libro Historia del teatro Smart. Treinta años de una empresa al servicio de la cultura (1924-1954), se destacan: Pablo Acchiardi, Elías Alippi, Daniel de Alvarado, Pedro Aleandro, Juan Bono, José Casamayor, Luis Corradi, José F. Podestá, José Sassone, entre otros. En cuanto a los artistas que debutaron en el escenario del Smart, se menciona: el teatro infantil de Angelina Pagano, Luis Arata, Enrique Muiño, Florencio Parravicini, Roberto Casaux. Mario Soficci y Enrique Gustavino organizaron una compañía llamada Arte Moderno (suponemos en 1935) Mecha Ortiz, Luis Arata, Fanny Navarro, Tita Merello y Guillermo Bataglia (Filomena Marturano), Juan Carlos Thorry, Analía Gadé, Camila Quiroga. Por último, también se destaca la participación de renombrados escenógrafos: Gómez y Peralta, Armando Colli, Bermejo, Ferrarotti, Saulo Benavente y Gori Muñoz. Tal como podemos observar, la dirección a cargo del matrimonio Podestá-Ballerini supo establecer un abanico innovador de figuras del espectáculo, así como también, evidenciar los nombres ya consolidados del campo teatral durante las décadas del 20 al 40, a fin de producir no sólo un repertorio de obras nacionales e internacionales importantes, sino también un conglomerado estético que da cuenta de los cambios que se produjeron al interior de las compañías teatrales, en particular, y el campo teatral, en general. En este sentido, las compañías- familias que conformó Blanca Podestá dejan atrás el modelo textual gauchesco y nativista de su padre y su tío Pepe, se vincula con la estética naturalista más cercana a su tío Pablo, al mismo tiempo que logra consolidar los procedimientos propios de la actuación culta y que podemos confirmar gracias a los materiales reunidos en la Discoteca Dramática Documental del INET.

En efecto, el sitio web del Instituto Nacional de Estudios de Teatro informa que: "está compuesta por grabaciones en discos de síntesis de obras dramáticas producidas por el INET entre 1960 y 1966. Esta Discoteca fue creada por iniciativa del entonces director del INET Alfredo de la Guardia. Los discos fueron grabados en los estudios de Radio Nacional por los actores que las estrenaron o representaron en el momento de su estreno, precedidas por las palabras de sus autores, siempre que ello fuera posible. Si no lo era, eran sustituidos por unas palabras críticas sobre el dramaturgo y por actores que hubieran representado la obra en otra oportunidad o afines a las piezas." (https://inet.cultura.gob.ar/noticia/discoteca-dramatica-documental/)

Así lo escuchamos en Gigoló de Enrique García Velloso, obra estrenada en el Teatro Smart el 14 de mayo de 1925. En las escenas seleccionadas para su grabación encontramos a: Blanca Podestá como Clara, Daniel de Alvarado como Armando, Juan Bono como Miguel, Mario Danesi como Ezequiel y Estela Vidal como Marcela y Perla Santalla como Albertina. En estas escenas, en las cuales Blanca Podestá representa 
a una madre que es pretendida por un "mozalbete" propenso al alcohol, las drogas y las mujeres -tal como lo define uno de los personajes- podemos reconocer en la voz de la actriz un ritmo pausado y sincopado que produce una melodía que encadena las palabras y las vierte en la escena sin exabruptos ni excesos. Asimismo, en esa musicalidad establece un guiño sutil y de complicidad con las señoras de buena alcurnia de la época, sin buscar la comicidad, sino, por el contrario, expresando un cierto patetismo. A la vez, retardando las pausas y encabalgando las palabras expresa los sinsabores que atraviesa su personaje, que tanta repercusión tuvo en la crítica del momento. Así, sosteniéndose en la dicción de sus discursos, en la articulación y la declamación no artificial (aspectos que seguramente heredó de la poética actoral popular), Blanca Podestá articula este drama en tres actos que según las palabras de su propio autor y enunciadas en el material audiovisual del INET es "una obra de dolor, amor y de muerte."

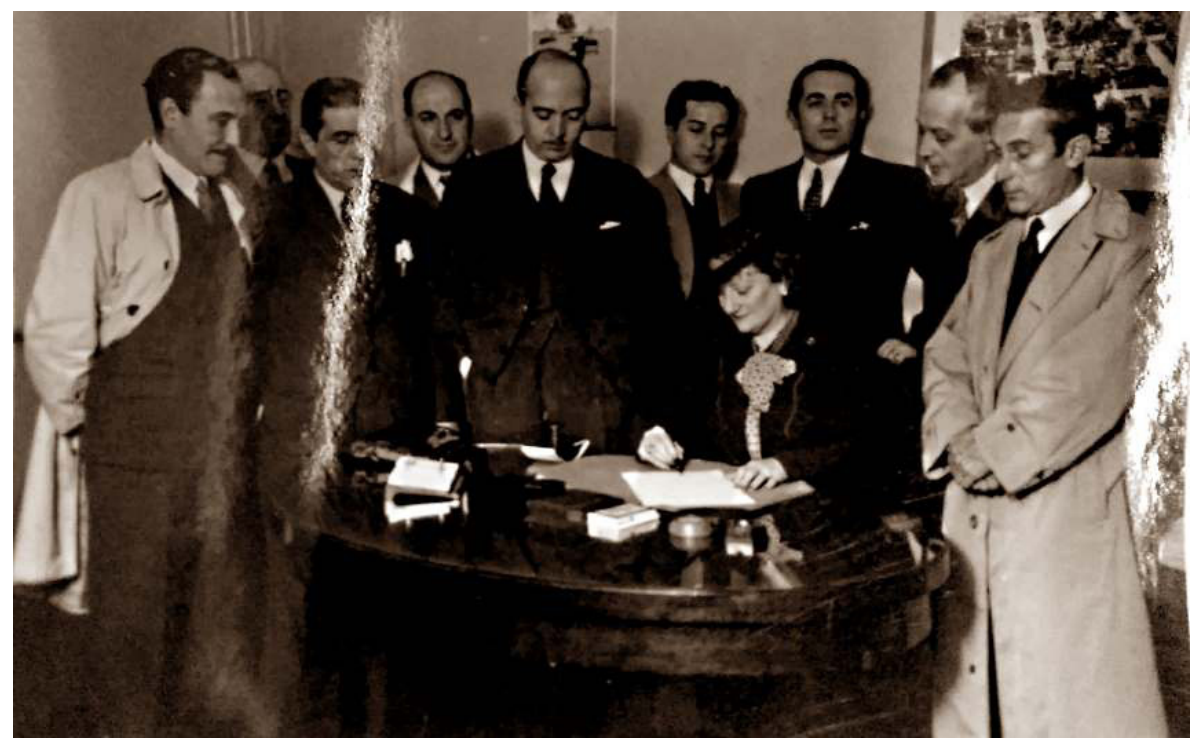

Blanca Podestá en la firma de un contrato laboral en el Smart, 1927.

Con respecto a los vínculos laborales y la situación de los trabajadores artísticos en este contexto del campo teatral argentino, encontramos un aporte fundamental para el estudio de las relaciones de los empresarios teatrales y el modo de planificar las temporadas en función de las ganancias. Esta información nos la brinda una carta del actor argentino Florencio Parravicini, quien además fue empresario teatral y concejal por el partido Gente de Teatro entre 1926-1928, a Alberto Ballerini. La correspondencia hallada en la Sección Manuscritos del INET y fechada el 28 de noviembre de 1940 es productiva para pensar los aspectos antes dichos como así también para dar cuenta de las condiciones de los seguros y cuestiones médicas de los artistas. Con respecto al primer punto, Parravicini le propone a Ballerini una obra extranjera que está terminado de traducir y, posteriormente a las autorizaciones pertinentes, la estrenarían bajo el nombre de ambos. De esta manera cobrarían derechos de autor por la pieza que según palabras del actor: "tiene todo lo que tienen que tener para ser un éxito" para que se estrene en el verano "y vivan de ellas durante el invierno". El segundo punto que abarca la carta es el que refiere a una enfermedad que aqueja a Parravicini y que lo tiene en reposo por orden médica durante tres meses. Su convalecencia, según sus propias palabras, es comparable a que Ballerini tenga cerrado el teatro por tres meses. Estas afirmaciones y confirmaciones ponen en evidencia un aspecto que hasta el día de hoy sigue siendo un problema para los artistas del espectáculo: la casi inexistencia de seguros laborales y médicos. Tanto en el pasado como en la actualidad los únicos seguros garantizados son los que refieren a los teatros y las salas. Poseer 
un seguro de vida y un seguro médico ha sido y es una excentricidad de pocos. Tal como lo hemos observado en otros estudios (Noguera, 2020), en la actualidad para asegurar al artista se evalúan ciertos aspectos relativos a sus antecedentes en la gira o en presentaciones anteriores, a fin de observar si las cancelaciones han sido una constante o no. Si esta es la situación en la contemporaneidad, damos por descontado que las dificultades que se presentaron en el pasado de nuestro campo teatral argentino fueron aún mayores, debido a la inexistencia de reglamentación de estos aspectos a pesar de las ya presentes agrupaciones gremiales artísticas.

Retomando la trayectoria de Blanca Podestá, entre 1941 y 1950, ella formó parte de la compañía del Teatro Nacional Cervantes, pero en 1949 regresó a la actuación en su querido Teatro Smart. En 1952, cuando falleció Ballerini, Blanca asume la dirección del teatro y se convierte en una de las pocas mujeres que llevó adelante la tarea de empresaria teatral. Señalamos que el trabajo femenino teatral sólo estaba destinado para la actuación ya sea como actriz principal, secundaria o cabeza de compañía. La dirección artístico teatral, hasta muy entrado el siglo XX, como así también las tareas técnicas (iluminación y vestuario) sólo eran desempeñadas por hombres. El rol de empresaria teatral, inclusive hasta la actualidad, es un trabajo poco frecuentado por las mujeres y por ello podemos afirmar que Blanca fue una pionera. No obstante, y en relación con el trabajo femenino, en especial el que refiere a las actrices en el período que aquí estamos analizando (e incluso en la actualidad) dista bastante de los logros en cuanto a los derechos laborales que fueron adquiriendo las mujeres trabajadoras de otros rubros desde 1907. En ese año se aprobó en Argentina un proyecto de ley que establecía una "jornada de ocho horas para las mujeres y menores de edad, condiciones mínimas de salubridad, descanso dominical, igual remuneración por igual trabajo, licencia prenatal y postnatal, tiempos de descanso para el almuerzo y para amamantar en el horario de trabajo y prohibición del trabajo nocturno para las mujeres" (Durán y Beatriz, 2014:4). Esas diferencias en cuanto a la jornada laboral y el descanso en el trabajo actoral, las podemos observar a partir del artículo "El día de un actor y una actriz", publicado en la revista Caras y caretas del 5 de octubre de1912, el cual refiere a los artistas Pablo y Blanca Podestá. En estas "biografías de un día en la vida de dos famosos y consagrados trabajadores del espectáculo" se deja ver que, a pesar de las diferencias con las jornadas laborales de un obrero o un político (tal como lo refiere el artículo), las responsabilidades sociales son las mismas. No obstante, se señalan las particularidades de la profesión que están marcadas, sobre todo, por las horas diferentes del sueño de los artistas. Así, se evidencia cómo el poco descanso está determinado por las extensas jornadas de trabajo que incluye los ensayos a partir de las 13 hs. para el caso de Blanca Podestá de Ballerini. Los ensayos con ropa de calle y con presencia del autor y director transcurren hasta las $18 \mathrm{hs}$. y de 20 a 24 hs., aproximadamente, duran las funciones teatrales. Ese mismo artículo está acompañado por fotografías de los artistas y muestra una foto de Blanca y su esposo en la habitación matrimonial ensayando la letra de la obra a la 1 de la mañana. Estos datos, como muchos otros que aparecen en reportajes, cartas y estudios sobre la época evidencian que, si bien los honorarios de los artistas se discriminaban según la posición jerárquica que tenían al interior de la compañía, no había discriminación en lo que respecta a las intensas horas de trabajo. Así lo explica Cilento en el estudio que realiza sobre Ballerini: “(...) en su inicio junto a Podestá no recibía dinero alguno y sólo después ganaría una cuarta parte de lo asignado para los actores principales." (2009:51) (2009:51)

En 1953, Blanca Podestá, ya consolidada en su lugar de actriz y empresaria, recibió el título de socia honoraria otorgado por la Asociación de Administradores Teatrales Argentino (ADATA) en reconocimiento a su gran desempeño, colaboración y generosidad en este rubro. Posteriormente, en noviembre de 1964, recibió el carnet de socia 
fundadora de la Asociación Argentina de Actores evidenciando así su compromiso y trabajo continuo en la profesión. La actriz y empresaria teatral, que estrenó más de ochenta obras nacionales e internacionales, dirigió compañías, fundó un teatro y llevó en su sangre la herencia artística de las primeras compañías-familias en argentina, falleció en Buenos Aires en mayo de 1967. Grandes homenajes se rindieron a la inolvidable actriz, su teatro pasó a llevar su nombre y en las palabras de un poema escrito por un admirador y en las de un espectador (Archivo Manuscritos, INET) leemos aquello que significó para su público:

\author{
Blanca \\ Maestra de maestros \\ Incansable e insuperada \\ Directora de arte dramático \\ Después de la gira triunfal \\ Por cien escenarios argentinos \\ Llevarás a la calle Corrientes \\ El perfume agreste \\ De nuestros campos \\ Y el polvo de todos los caminos. \\ Mario Cifarell \\ Y sobre todo, iporque su nombre significa la puerta \\ por donde el teatro argentino entró al mundo! \\ Un espectador.
}

Como vemos la relación afectiva no sólo fue una característica de la unión matrimonial y artística de Blanca y Alberto, sino también fue fundante en la relación que los artistas de la época establecieron con su público. Así lo observa Pellettieri, al analizar las características del campo teatral moderno argentino y en la cual los trabajos de Blanca y Alberto se inscribieron: "El espectador integraba simbólicamente a los actores a su núcleo familiar y establecía con ellos una corriente afectiva que excedía ampliamente los límites de la valoración que hacía de sus cualidades actorales propiamente dichas" (2002: 94)

\title{
Palabras finales
}

El estudio de los afectos y sentimientos (el objeto de estudio y su definición es uno de los problemas y temas con el que se enfrentan los investigadores) posee una larga trayectoria en las Ciencias Sociales. Desde la filosofía antigua hasta la actualidad, desde múltiples enfoques y disciplinas (sociología, antropología, psicología, historia, literatura, estudios del trabajo, etc.), se ha contemplado cómo la relaciones emotivas y afectivas se encuentran presentes de manera determinante en las prácticas sociales y artísticas no respondiendo de manera radical a factores biológicos. María Bjerg ,en relación con las investigaciones actuales, y a partir de la genealogía de estudios sobre los afectos que plantea en su artículo, afirma que: "Sustraer las emociones de los enfoques construccionistas y lingüísticos, recuperar la materialidad del cuerpo y del mundo y repensar la dicotomía naturaleza/cultura son algunos de los retos que enfrenta la historia de las emociones por estos días" (2019:16). Por su parte, con respecto al giro afectivo, Leonor Arfuch señala que a partir del siglo XXI este affective turn: "parece haber ganado terreno en la reflexión de las ciencias sociales -en particular en el mundo anglosajón en sintonía con ciertos cambios significativos de las sociedades contemporáneas, que se manifiestan tanto en la vida cotidiana, los comportamientos y los hábitos como en relación con la política. "Vivimos en una sociedad afectiva" -dicen algunos- una condición que se despliega en cantidad de 
registros donde los medios tienen indudable primacía: talk shows, realities, expansión de lo auto/biográfico y lo subjetivo, culto a la intimidad, exaltación confesional en las redes sociales, hibridación de géneros, voyeurismo y emociones vicarias en la TV, justicia restaurativa -y juicios mediáticos- (...)".(2007: 246)

Estas perspectivas teóricas sobre los afectos nos permitieron acceder de manera diferente al pasado teatral argentino a fin de comprender no sólo los aspectos estéticos que lo determinaron sino, sobre todo, comprender los vínculos afectivos y económicos que los y las artistas de la época establecieron al interior de las compañías que formaron. Así, estos aportes teóricos y -fundamentalmente- a partir de los materiales biográficos de artistas hallados en el INET, en general, y en el Fondo Jacobo de Diego, en particular, nos permitieron trazar, siguiendo a Arfuch (2007), un espacio biográfico afectivo que, junto a esta autora, entendemos como la construcción de un corpus de trabajo basado en materiales disímiles en los cuales la subjetividad se revela y se construye por medio de narrativas biográficas o autobiográficas. Así, este espacio biográfico afectivo nos posibilitó entender el modo de funcionamiento de las compañías- familias en el entramado social, cultural y artístico de la Argentina de principios a mitad de siglo XX a partir de dos representantes paradigmáticos del árbol genealógico de los Podestá: Blanca y Alberto. Las características principales de este tipo de compañías se sustentaron en los lazos de la propia sangre como así también en las nuevas asociaciones que se plantearon a través de nuevos contratos: los matrimoniales. En este sentido, los vínculos laborales se constituyeron a partir de la herencia, pero también de las elecciones afectivas que los miembros de las familias establecieron, en la mayoría de los casos, al interior del mismo campo artístico. Esto permitió el reaseguro no solo de los saberes artísticos, sino también de los bienes económicos obtenidos en las trayectorias artísticas. Al mismo tiempo, y tal como lo hemos analizado en otros estudios, las rupturas afectivas de los integrantes y fundadores de las compañías-familias (aquéllas icónicas en la historia de nuestro pasado teatral como fue la de José y Jerónimo en 1902; la de José y Pablo en 1906) permitieron la reubicación en el mapa teatral de la Argentina en este período a la vez que posibilitó la proliferación de nuevas compañías-familias que reprodujeron sus mismas formas de organización, disciplinamiento y modos de producción, pero produciendo importantes renovaciones estéticas. 


\section{Dibliografía}

》Anónimo. Comentarios dialogados algunos hechos de teatro, actores, etc. Manuscrito mecanografiado inédito. Archivo Manuscritos del INET.

"Arfuch, L. (2013). Memoria y autobiografía. Buenos Aires: FCE.

»Arfuch, L. (2007). El espacio biográfico. Dilemas de la subjetividad contemporánea. Buenos Aires: Fondo de Cultura Económica.

»Bjerg, M. (2019). Una genealogía de la historia de las emociones. Quinto Sol, 23(1), 1-17.

»Cilento, L. (2009). Alberto Ballerini. Diccionario Biográfico y estético del actor en Buenos Aires. Volumen I. El actor popular, antecedentes y evolución. Buenos Aires: Galerna. 50-52

"Durán, R., \& Beatriz, A. (2014). Los sentidos del trabajo femenino en la Argentina del 1900. In VIII Jornadas de Sociología de la UNLP. Departamento de Sociología de la Facultad de Humanidades y Ciencias de la Educación.

» Mauro, K. (2018). “Entre el mundo del arte y el mundo del trabajo. Herramientas conceptuales para comprender la dimensión laboral del trabajo artístico". telondefondo. Revista de Teoría y Crítica Teatral, año XIV, (27), enero-junio 114-143. http://revistascientificas.filo.uba.ar/index.php/telondefondo/article/ view/5097/4611

»Mogliani, L. (2021). Un precursor de la dirección teatral: Ezequiel Soria y su labor en la compañía de Pepe Podestá. Perspectivas sobre la dirección teatral: teoría, historia y pensamiento escénico. Córdoba: Universidad Nacional de Córdoba.

"Noguera, L. (2020). “¿Yendo a lo seguro? Condiciones de seguridad y situación de los seguros laborales de los artistas del espectáculo en Argentina." Revista Latinoamericana de Antropología del Trabajo, 4(8), 8.

» Noguera, L. (2018). Las condiciones laborales en las compañías teatrales de José Podestá (1872-1937). telondefondo. Revista de Teoría y Crítica Teatral, año XIV, (27), 144-162.

" http://revistascientificas.filo.uba.ar/index.php/telondefondo/article/ view/5098/4612

》Pellettieri, O. (2002). Historia del teatro argentino en Buenos Aires. La emancipación cultural (1884-1930). Volumen II. Buenos Aires: Galerna.

»Podestá, B. (1951). Algunos recuerdos de mi vida artística. Buenos Aires: Bartolomé U. Chiesino.

»Podestá, J. (2003). Medio siglo de farándula. Memorias de José Podestá. Buenos Aires: Galerna.

»Podestá. M. E. (1985). Desde ya y sin interrupciones (Memorias). Buenos Aires: Corregidor

"Vargas Islas, L. E (1996). El amor ¿rehén de familia? Recuperado el 18/12/2020: https://biblat.unam.mx/hevila/TramasMexicoDF/1996/nog/9.pdf 